\title{
MODELING AND SIMULATION OF A MATTRESS PRODUCTION LINE USING PROMODEL
}

\author{
Mohammad H. Khalili \\ School of Computing, Science and Engineering \\ University of Salford \\ The Crescent, Salford, \\ Greater Manchester, M5 4WT, UK
}

\author{
Farhad Zahedi \\ School of Computing, Science and Engineering \\ University of Salford \\ The Crescent, Salford, \\ Greater Manchester, M5 4WT, UK
}

\begin{abstract}
Understanding the current manufacturing setup and accurately predicting the performance of a system over time makes modeling and simulation an ideal tool for systems' planning. This case study aims mainly at exploring the application of modeling and simulation (M\&S) in order to evaluate and provide performance results that could help measure the capacity and the capability of an existing mattress production line, and to further investigate whether the production line could cope with the firm's expansion plan over the next five years. The simulation model was built and analyzed using the ProModel discrete-event simulation software. The analysis found that the current production setup could not cope with the demand over the next five years. Therefore, potential improvements within the production line were identified and implemented in an improved scenario model. The results indicated that the new system was able to meet the new demand and cope with the proposed expansion plan.
\end{abstract}

\section{INTRODUCTION AND LITERATURE REVIEW}

M\&S has been a useful tool to design, analyze, evaluate and improve manufacturing systems for decades (Sona et al. 2003). "Its unique ability to accurately predict the performance of complex systems makes it ideally suitable for system planning," stated recently by Harrell et al. (2012).

Over the last couple of decades, parallel to the dramatic technological development, several business and information technology support companies have developed and delivered commercial M\&S packages to the market. M\&S software packages, like ProModel, ARENA, SIMUL8 and Plant Simulation, opened the new horizon for manufacturers and gave them the opportunity to use M\&S in process optimization and decision support systems.

$M \& S$ is a powerful and useful tool for the manufacturing environment. Clark (1996) emphasized the importance of M\&S in manufacturing by stating that "Manufacturing is one of the earliest simulation application areas and remains as one of the most popular application areas." Williams and Narayanaswamy (1997) observed that "Simulation has a long and strong track record in analysis of manufacturing systems whose complexity and interaction of components defy closed-form methods." Such statements prove the value and the importance of $M \& S$ in the manufacturing environment.

The applications of M\&S in manufacturing are really vast. Abu-Taieh and Sheikh (2009) found that 14 percent of $M \& S$ packages available in the market were targeting the manufacturing sector. $M \& S$ in the manufacturing sector includes non-developed system modeling and current system development and analysis. The analysis of such systems included scheduling, sequencing, processing, material handling and resources planning. M\&S is also used in the warehousing and distribution centers, which are major parts of the logistics sector. M\&S can help the manufacturing sector in the Job Routing, Factory Flow, 


\section{Khalili and Zahedi}

Plant Layout, Capacity Planning, Staffing Optimization and Machine Reliability Effect (Arena Simulation Software, 2012).

Qayyum and Dalgarno (2012) used M\&S to improve the capacity of a manufacturing facility, of a Small and Medium Enterprise (SME). Clark (1996) demonstrated the applications of M\&S in manufacturing systems. He developed a model for a mould production cell in which he wanted to ensure that the cell met the design objectives, and to assist in specifying equipment performance capabilities. He concluded that "Simulation is a powerful approach to modeling manufacturing systems in that many complex and diverse systems can be represented." For example, if a production team in a manufacturing firm, with more than a hundred processes and resources, was required to identify problems such as bottlenecks, machine utilization and resource allocations, it would be a really difficult task to answer these questions without the use of M\&S.

The concept of bottleneck management for manual automobile assembly systems through simulation was recently developed by Dewa and Chidzuu (2012). They created the required model with a focus on improving automobile assembly systems in batch mode. A complete time study was performed to collect the input data required for each workstation and operator to perform the task. After verification and validation, the model was analyzed with a special focus on the effect of vehicle sequencing, the effect of batch sizes, the individual vehicle models, the effect of a subassembly and the effect of downtime on the bottlenecks. They concluded that "the machine with the highest degree of utilization does not necessarily have to be the bottleneck. When the model is simulated, one could trace the bottleneck by finding out which machine is blocked most. The machine next to this one is the bottleneck."

Quackenbush (1968) and Silva et al. (2000) observed that it is vital to have people from the industry throughout the entire project to help the model developer and emphasized the importance of accurate information (data) in simulation projects.

Nikoukara and Paul (1999) emphasized that the selection of suitable simulation software is also of considerable importance to any simulation project. They, along with Tewoldeberhan et al. (2002), were concerned that the selection a suitable simulation package will be more difficult as the quantity and quality of those software packages increases. Thus, the need for a methodological approach for selecting an appropriate simulation package using appropriate evaluation tools and techniques was apparent.

Grant (2002) and Abu-Taieh and Sheikh (2009) provided extensive surveys in the literature showing that the ProModel software was best suited to business process re-engineering and workflows. Harrell and Price (2002) have argued that ProModel is "designed to model manufacturing systems ranging from small job shops and machining cells to large mass production, flexible manufacturing systems, and supply chain systems." Lu and Wong (2005) also described ProModel as a powerful and easy-to-use manufacturing simulation tool for modeling all types of systems and processes.

Tearwattanarattikal et al. (2008) used ProModel software to compare the performance utilization of machines, characteristics of work-in-progress (WIP) and the ability to meet due dates. They defined the expanding capacity policy as "extra shift-working hours or increasing the number of machines." The physical layout was then chosen based on the space available for the WIP flow.

Based on our literature review, the new contributions of this paper are as follows:

(1) We develop and analyze a specific simulation model for an existing mattress production line;

(2) We analyze different output analysis approaches. Greater focus is given to identify suitable methods for determining the warm-up period and the number of replications;

(3) Through analyses of results we show how potential improvements could be identified and designed into an improved model.

\section{PROBLEM DESCRIPTION}

The company on which this research project was based is one of the fast-growing mattress manufacturing companies in the Persian Gulf region. Since 2010, the company started to follow an aggressive expansion 


\section{Khalili and Zahedi}

strategy with an aim to expand its presence into two new countries every year. The management at the company posed 'one big question', and that is whether the current manufacturing setup could cope with the expansion plan and meet the demand of the market over the next five years, as shown in Table 1.

To answer this question, the company agreed to measure the capacity and capability of its mattress production line based on some pre-defined performance measures, such as average throughput. M\&S was one possible way for measuring the capacity and capability of the production line. Since M\&S is an excellent way to study the performance of manufacturing systems, the company management decided to collaborate in a research project. As a result, it became possible to investigate the capacity and capability of the mattress production line and also to explore any opportunities for improvements.

Table 1: Demand projections of mattresses during years 2012-2016.

\begin{tabular}{|l|r|r|r|r|r|}
\hline \multicolumn{7}{|c|}{ The Demand Projections for the Years 2012-2016 } \\
\hline Year & 2012 & 2013 & 2014 & 2015 & 2016 \\
\hline Quantity/year & 172,693 & 192,948 & 215,371 & 240,259 & 267,857 \\
\hline Quantity/month & 14,391 & 16,079 & 17,948 & 20,022 & 22,321 \\
\hline
\end{tabular}

To model the production line using M\&S some key issues had to be resolved. Firstly, the detail level of the proposed simulation model, the accuracy of the collected data, and the key performance measures had to be discussed and agreed upon with the company. The second issue was to determine the steadystate behavior of the simulation model. Hoad et al. (2009) suggested considering two key issues in order to ensure the accuracy of the output parameters: "first, the removal of any initialization bias; second, ensuring that enough output data are produced." Nuyens et al. (1996) went further by stating that "the typical performance measures, output parameters of interest, such as, average throughput, average response time or system utilization must also be measured in steady-state."

The output result analysis enabled the identification of the transient period, the number of replications and the length of the simulation run. As part of the scope of the study, simulation output had to be analyzed thoroughly in order to identify the methods best suited to the study parameters. There were several methods available for analysis in the literature.

\section{MANUFACTURING SYSTEM DESCRIPTION}

The mattress production line is composed of five major departments: Spring, Foam, Quilting, Tailoring, and Mattress Build Up, as shown in Figure 1. To better understand the production process, various steps of constructing an innerspring mattress are described below.

The construction of a mattress starts with the production of coils in the spring department. Four automatic coiling machines are utilized to produce the required coils from raw steel wire. Chassis production is the next step in the mattress construction. Four semi-automated assembly machines are used to interconnect the coils in rows by helical wire. The number of coils in each row may differ based on the chassis size. For each assembly machine an operator is responsible for using the available buffer stock to feed coils into the assembly machine.

Before transferring the chassis to the clinching section, borders and corners are produced on frame bending and corner making machines. Both borders and corners are then transferred to a separate buffer stock near the clinching section. The clinching section is composed of five clinching tables. At each table an operator is responsible to collect one chassis, two frames, and six corners from assigned buffer stocks, attach them using a pneumatic clinching gun, and transfer the finished chassis to the mattress build up department.

While the chassis is built up in the spring department, the decorative cover that serves as the exterior for the top, bottom and sides of the mattress are produced in the quilting and tailoring department. First, quilted fabrics and borders are produced on giant automated CNC quilting machines in the quilting 


\section{Khalili and Zahedi}

section. Fabric, cotton felt, threads and foam roll are the raw materials required to produce both the quilted fabric panels and borders. The outputs of the machines are then transferred to the tailoring section.

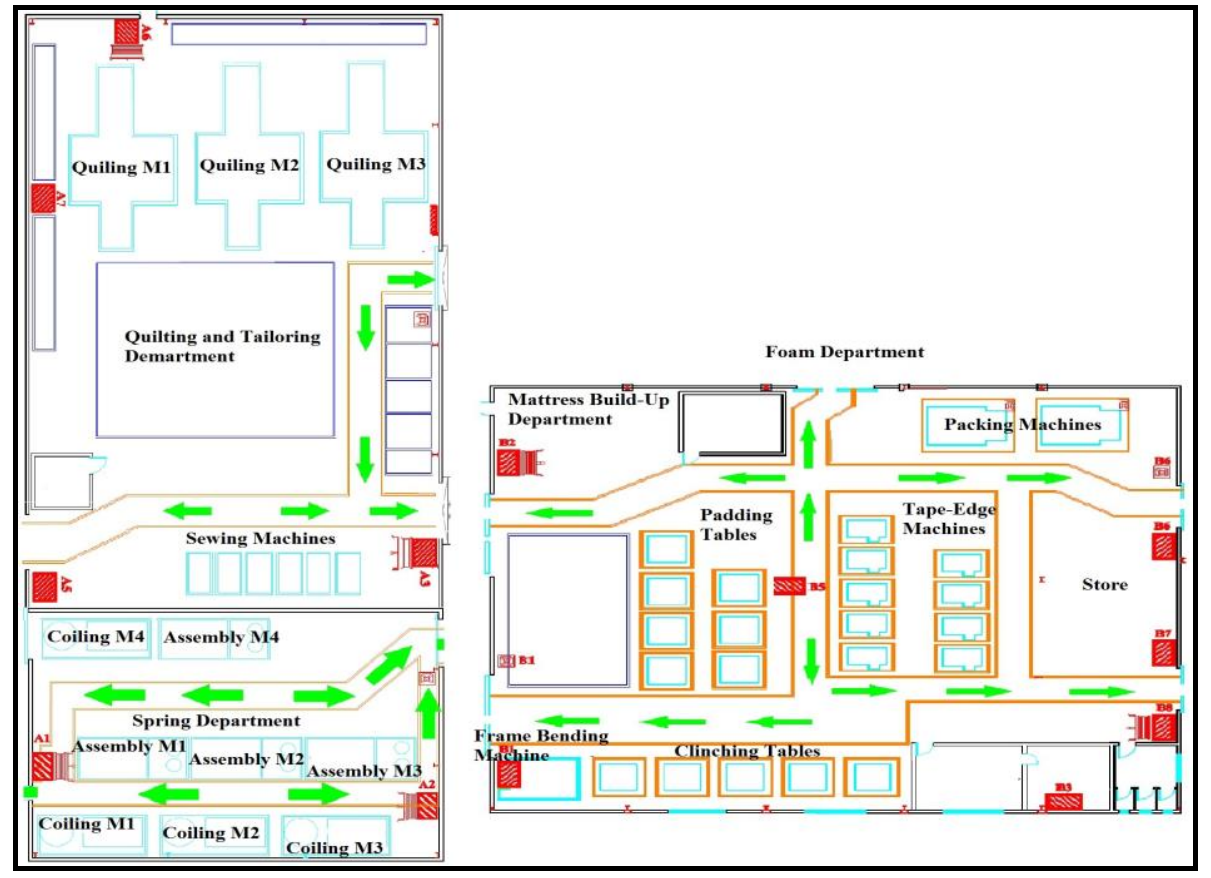

Figure 1: Production layout.

Six sewing machines, five panel sewing machines and one border sewing machine in the tailoring section are awaiting receipt of quilted fabric panels and borders. After sewing the quilted fabric panels and borders, product names change to ready panels and ready stitched borders, respectively. Attached borders and quilted fabric panels are then transferred to the mattress build up department.

The mattress build up department is the final stage of mattress construction where chassis, panels, borders and foam layers are assembled together to form a high-quality mattress. The department consists of three sections: padding, tape-edge and packing. In the padding section, seven operators work on seven padding processing tables to attach different layers of cotton felt, plastic mesh and foam sheets, which are received from the foam department, to the chassis. The produced item, called a padded mattress, is then transferred to the tape-edge section.

Nine tape-edge machines are used to manually feed the top, bottom, and side panels and a heavy-duty binding tape into the sewing machine as it moves around the padded mattress. The tape-edged mattress is then transferred to the packing section. Two semi-automated packing machines are utilized to pack the taped-edge mattresses. Once tags and labels are attached to the mattress, an operator inserts the mattress into the packing machine. Finally, the packed mattress is transferred to the finished goods store.

\section{INPUT ANALYSIS}

Collecting and analyzing data for specifying the corresponding inputs to a simulation model in an accurate, realistic and valid way is of paramount importance. However, it is a very laborious and timeconsuming task which in some cases can take up to several months (Weiss and Piłacińska 2005).

Figure 2 illustrates a schematic diagram of material flow in each of the spring, quilting and tailoring, and mattress build up departments. The flow chart was devised in order to help the model-building process, and to identify areas of interests, such as a list of all materials, machines and processing tables required for the study. 


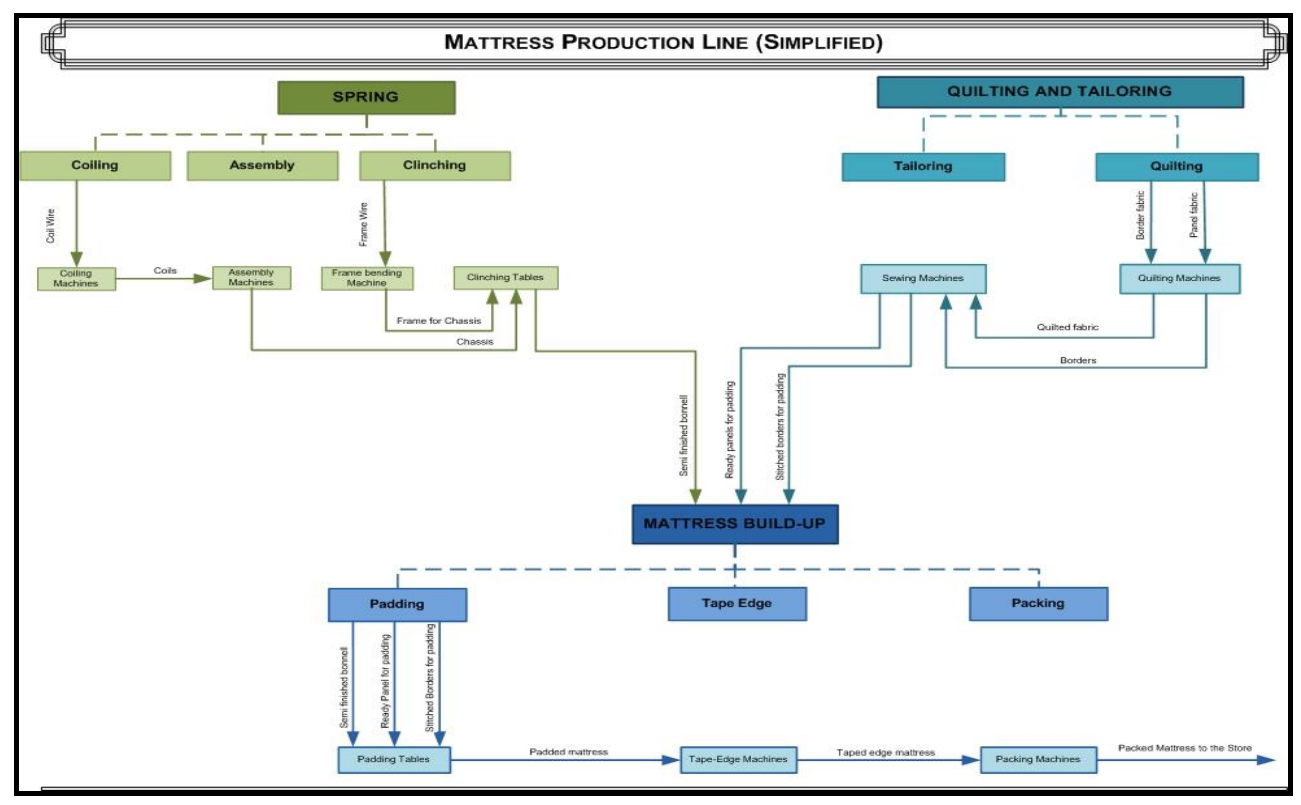

Figure 2: Revised material flow chart.

Table 2 shows that the production line consists of nine different machines and processing tables. Some are automated; others are either semi-automated or manual operations. Identifying the processing times of the automated machines such as the coiling and quilting, was a simple and straightforward task. It required finding the production capacity of each automated machine and converting it to a corresponding processing time as shown in Table 3.

Collecting data for calculating the processing times of the semi-automated machines and manual operations required special attention and a different approach. The time study technique was used to collect the required raw data for the study. Next, Stat::Fit, ProModel's input analyzer, was used to fit the data to different probability distributions.

Table 2: List of the machines and processing tables of the production line.

\begin{tabular}{|l|l|l|l|l|l|l|l|}
\hline \multicolumn{9}{|c|}{ List of the existing machines and processing tables } \\
\hline \multicolumn{3}{|c|}{} & Spring Department & \multicolumn{5}{|c|}{ Mattress Build Up Department } \\
\hline 1 & Type & Units & Machine Name & $\#$ & Type & Units & Machine Name \\
\hline 2 & Automated & 4 & Coiling & 6 & Manual & 7 & Padding \\
\hline 3 & Semi Auto & 4 & Assembly & 7 & Manual & 9 & Tape Edge \\
\hline 4 & Manual & 1 & Frame Bending & 8 & Semi Auto & 2 & Packing \\
\hline \multicolumn{2}{|l|}{} & 5 & Clinching & & & Tailoring Department \\
\hline 5 & Automated & 3 & Quilting & & & & Sewing \\
\hline
\end{tabular}

Processing times for each semi-automated machine and manual operation, as raw data, were inserted into the Stat::Fit input analyzer software. The software provided three goodness of fit tests, including ChiSquared, Kolmogorov-Smirnov and Anderson-Darling, to help select the best distribution for data. However, only the Kolmogorov-Smirnov and Anderson-Darling tests were used as they are applicable over the widest range of data. Table 4 contains a summary of all probability distributions of the semiautomated and manual operations and their corresponding expressions which were deduced from both Kolmogorov-Smirnov and Anderson-Darling tests. 
Table 3: List of all automated machines and their corresponding processing times.

\begin{tabular}{|c|c|c|c|c|c|c|}
\hline \multicolumn{7}{|c|}{ List of automated machines and their corresponding processing times } \\
\hline \multicolumn{5}{|c|}{ Spring Department } & & \\
\hline \# & & Machine & Capacity & Unit & Processing time for each coil & Unit \\
\hline 1 & Automated & Coiling 1 & 60 & coils/min & 0.016 & $\min$ \\
\hline 2 & Automated & Coiling 2 & 58 & coils/min & 0.017 & $\min$ \\
\hline 3 & Automated & Coiling 3 & 65 & coils/min & 0.015 & $\min$ \\
\hline 4 & Automated & Coiling 4 & 52 & coils/min & 0.017 & $\min$ \\
\hline \multicolumn{5}{|c|}{ Quilting and Tailoring Department } & & \\
\hline \# & & Machine & Capacity & Unit & Processing time for each panel or border & Unit \\
\hline 1 & Automated & Quilting 1 & 65 & meters $/ \mathrm{hr}$ & 1.36 & $\min$ \\
\hline 2 & Automated & Quilting 2 & 45 & meters $/ \mathrm{hr}$ & 1.46 & $\min$ \\
\hline 3 & Automated & Quilting 3 & 55 & meters $/ \mathrm{hr}$ & 1 & $\min$ \\
\hline
\end{tabular}

Table 4: Summary of probability distributions for semi-automated and manual operations.

\begin{tabular}{|c|l|l|l|l|l|l|l|}
\hline \multicolumn{7}{|c|}{ Processing times for machines and processing tables } \\
\hline$\#$ & \multicolumn{1}{|c|}{ Name } & Distribution & \multicolumn{1}{|c|}{ Expression } & $\#$ & \multicolumn{1}{|c|}{ Name } & Distribution & Expression \\
\hline 1 & Assembly M & Triangular & $\mathrm{T}(3,4.35,5.13)$ & 5 & Tape edge M & Weibull & $4+\mathrm{W}(2 ., 3.46)$ \\
\hline 2 & Frame bending M & Lognormal & $\mathrm{L}(0.452,0.11)$ & 6 & Packing M & Weibull & $\mathrm{W}(11.7,0.338)$ \\
\hline 3 & Clinching table & Beta & $\mathrm{B}(1.32,8.4,3,9.07)$ & 7 & Sewing M (Panels) & Weibull & $1+\mathrm{W}(4.37,0.564)$ \\
\hline 4 & Padding table & Beta & $\mathrm{B}(1.8,1.38,12,15)$ & 8 & Sewing M (Borders) & Weibull & $\mathrm{W}(6.13,0.324)$ \\
\hline
\end{tabular}

\section{SIMULATION MODEL}

Building a credible and valid simulation model requires specific steps to be followed. It is well known that the starting point for creating a simulation model is the establishment of assumptions. The modelbuilding process can get much easier when reasonable assumptions are made (Clark and Krahl 2011). Some of the key assumptions made are as follows:

- The analyzed production line is considered as a single product line. The product specifications are: a mattress of size $100 \mathrm{~cm}$ x $200 \mathrm{~cm}$ with average complexity.

- There are no maintenance activities and equipment failures, such as, machine breakdowns. Also a zero rate of defects has been assumed.

- There is a continuous and infinite supply of raw materials at the Coiling, Quilting and Frame bending machines.

- The material handling is performed manually. Operators are always available during their shifts.

- During material handling, the operators walk through assigned walkways and follow the same route every time they perform a job. They also return to their assigned locations after finishing their tasks.

- The amount of work-in-process and buffer-stock at each station is infinite.

After creating a full list of assumptions, the simulation model was built. The first step was to create the 'locations' which include machines, processing tables and WIPs. The second step was to define the 'entities' such as raw materials and other WIP products. Creating the arrival pattern of the entities was the third step. The next step was to expand the model by adding 'resources' and the corresponding 'path networks' needed to move entities from one location to another. Finally, the 'processing' logic of the entities at different locations was defined. Clark and Krahl (2011) suggested that the model-building process starts from small and manageable pieces: "start small, verify and validate, add more, verify and validate and so on." Figure 3 shows a screen capture of the model being run. 


\section{Khalili and Zahedi}

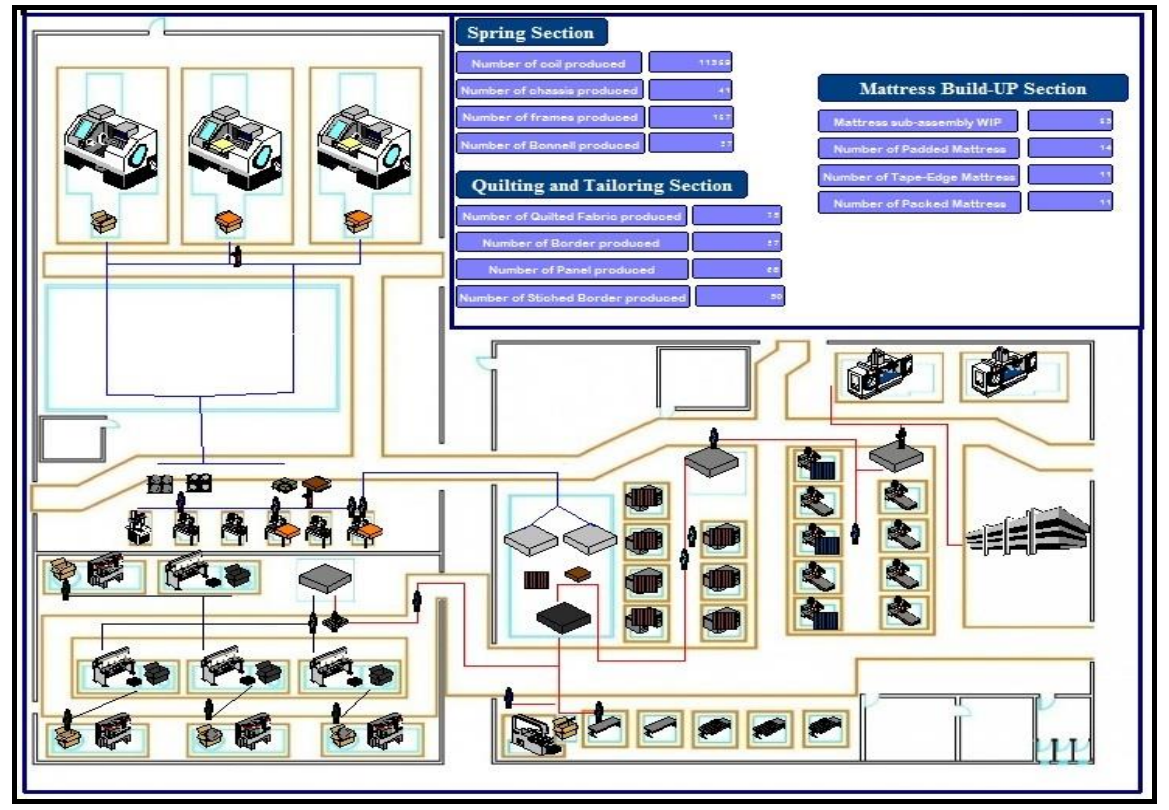

Figure 3: The production model built using ProModel.

Most of the simulation models designed for manufacturing systems are intended to provide information about the steady-state behavior of the system. Such models are known as non-terminating simulation models. And for a non-terminating simulation the output normally, but not always, reaches steady-state if the model is run long enough. In other words, steady-state behavior of a non-terminating system means that the statistical variation in the output data does not change over time (ProModel Corporation 2011, Alexopoulos 2006). To make sure the system has reached steady-state, initialization bias should be detected and removed. Moreover, it should be ensured that enough output data are produced to obtain an accurate estimate of the system's performance (Robinson 2007). Removing the initialization bias from the simulation output data is done by identifying the warm-up period. After removing the initialization bias, the accuracy of the system's performance is achieved by identifying the number of replications and the length of the simulation model run (Carrie 1988).

The starting point will be the selection of the warm-up period. Hoad et al. (2008) evaluated 44 warmup period methods to find the best method for their automated output analyzer software, AutoSimOA. They used the following criteria in evaluating and selecting the most suitable method: accuracy and robustness of method, simplicity of the model, ease of potential automation, generality, number of parameters required, and computing time. The study results revealed that Marginal Standard Error Rule (MSER-5) using batches of 5 data points performed the best and provided the most consistent results. MSER-5, selects the warm-up period that minimizes the width of the confidence interval (CI) about the truncated sample mean. Hoad et al. (2008) concluded their study by stating that "MSER-5 does not require estimation of any parameters and can function adequately without user intervention. It is quick to run and fairly simple to understand. It is therefore an ideal candidate for automation and incorporation into an automated analyzer system."

Therefore, the same method was used to identify the warm-up period for our study. And the model's throughput was chosen as the output parameter for determining the warm-up period.

As mentioned earlier, the throughput of the model was the number of packed mattresses produced. The initial simulation run length was set to 550 hours. This number represented an equivalent number of hours of production time in one month. The number of replications was also set to five as suggested by Hoad et al. (2011). After running the simulation model for the specified period, the warm-up period was 
identified as 5 hours, as shown in Figure 4. The warm-up period was added to the simulation run time for determining the number of replications required to achieve a $95 \%$ confidence level for the output results.

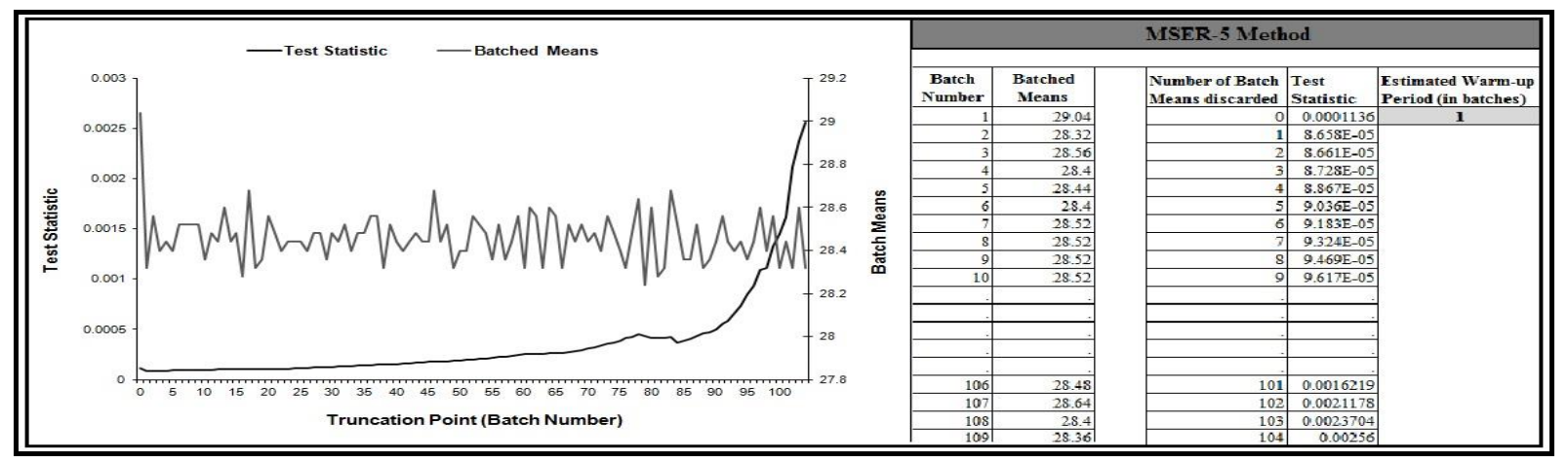

Figure 4: The MSER-5 implementation to identify the warm-up period.

Hoad et al. (2007) suggested that the advantage of the Confidence Interval method is "that it relies upon statistical inference to determine the number of replications required." The method allows looking ahead by, performing a set number of five extra replications to check whether the precision of the data remains within the acceptable percentage. By analyzing the graph shown in Figure 5, the point at which the fluctuations of the data reduced to a minimum and the percentage deviation is relatively close to the significance level, was identified. The point representing the number of required replications was identified as 20 .

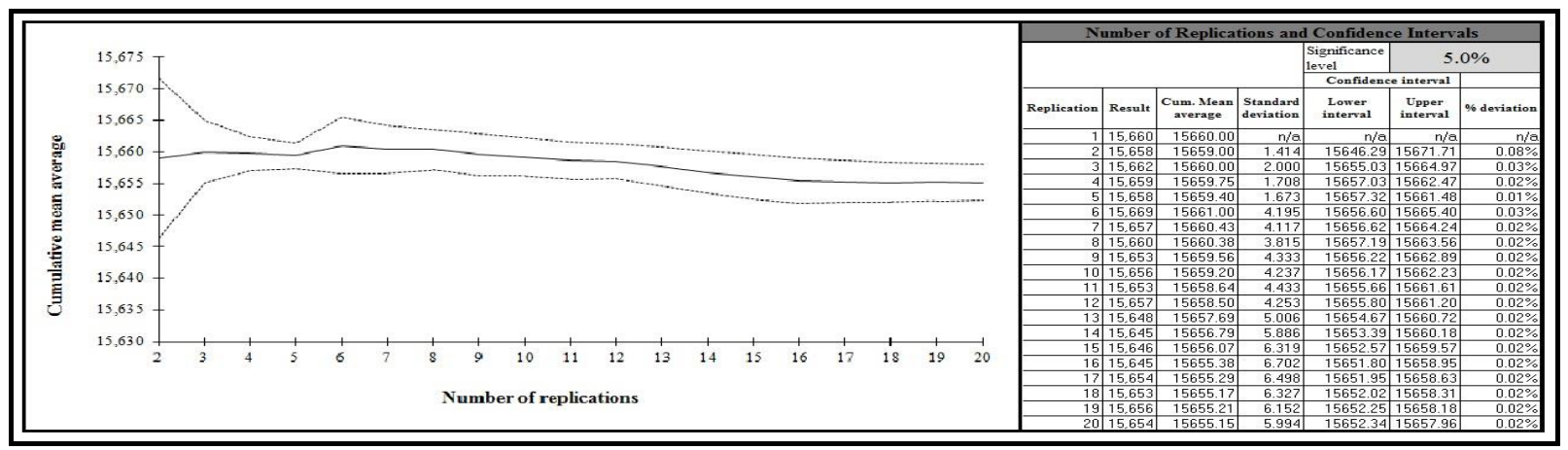

Figure 5: The Confidence Interval method used to determine the number of replications.

ProModel Corporation (2011) suggests that "it is usually a good idea to run the simulation enough times to let every type of event (including rare ones) happen at least a few times if not several hundred." They argue that "the longer the model is run, the more confident you can become that the results represent the steady-state behavior of the simulation model." Therefore, the simulation run length was set to 6,600 hours, equivalent to one full operational year.

\section{SIMULATION RESULTS}

After removing the initialization bias from the output results by identifying the warm-up period as 5 hours and running the simulation for 6,600 hours with 20 replications, the following results were obtained. The presented results were based on the data obtained from the Output Viewer of ProModel software. The most important performance measure was the total throughput (number of packed mattresses) of the system. Table 5 shows the status of some of the entities involved in the production line including the packed mattresses. 


\section{Khalili and Zahedi}

Table 5: Status summary of the entities involved in the production line.

\begin{tabular}{|l|r|r|r|r|}
\hline \multicolumn{5}{|c|}{ Entity summary } \\
\hline Name & Total Exits & \multicolumn{1}{|c|}{$\begin{array}{c}\text { Average Time in } \\
\text { System (Min) }\end{array}$} & $\begin{array}{c}\text { Average Time } \\
\text { Waiting (Min) }\end{array}$ & $\begin{array}{c}\text { Average Time in } \\
\text { Operation (Min) }\end{array}$ \\
\hline Coil & $6,551,174$ & 3.10 & 2.73 & 0.02 \\
\hline Chassis & 27,993 & 6.69 & - & 4.16 \\
\hline Frame & 72,994 & 0.68 & 0.23 & 0.45 \\
\hline Ready Panel & 47,340 & 9.17 & 4.70 & 2.91 \\
\hline Packed Mattress & 15,653 & $8,846.15$ & $3,138.71$ & 22.39 \\
\hline
\end{tabular}

Comparing the number of packed mattresses with the demand for year 2012, as shown in Table 1, confirmed that the mattress production line was able to meet the demand during the first year of the expansion plan. However, the production capacity was not enough to cover the demand for the following years and a huge shortage in the production output was expected. After analyzing all the performance measures of different entities, machines, processing tables and operators many opportunities for improvements were identified. To develop an improved scenario which can help increase the throughput and also increase the efficiency of the production line in general, the utilization of several machines and operators were reviewed and considered.

Table 6: List of suggested alterations in the new simulation scenario.

\begin{tabular}{|c|c|c|c|}
\hline \multicolumn{4}{|c|}{ Improved scenario } \\
\hline \# & Section & Description & Change \\
\hline 1 & Tailoring & Remove two sewing machine (panel) & $5 \rightarrow 3$ \\
\hline 2 & Tailoring & Reduce the number of operators in the sewing machine (panel) by two & $5 \rightarrow 3$ \\
\hline 3 & Frame Bending & Add another operator to the frame bending machine & $1 \rightarrow 2$ \\
\hline 4 & Padding & Increase the number of padding tables by three & $7 \rightarrow 10$ \\
\hline 5 & Padding & Add five operators to the padding tables & $7 \rightarrow 12$ \\
\hline 6 & Tape-Edge & Remove three tape-edge machines & $9 \rightarrow 6$ \\
\hline 7 & Tape-Edge & Reduce the number of tape-edge operators by three & $9 \rightarrow 6$ \\
\hline 8 & Packing & Remove one of the packing machines & $2 \rightarrow 1$ \\
\hline 9 & Packing & Reduce the number of packing operators by one & $2 \rightarrow 1$ \\
\hline
\end{tabular}

A series of experiments were carried out to identify which alterations could enhance the systems' performance and increase throughput. Based on various results obtained, the above changes were finally made to the model in an improved scenario, as shown in Table 6.

As illustrated, five sections of the production line were considered; however, only alterations 3, 4 and 5 which are related to frame bending and padding sections were directly involved in increasing the throughput. Based on alteration 3, another frame bending operator was added to the frame bending machine. Alterations 4 and 5 suggest that three additional processing tables and five padding operators were needed in the padding section. The other changes; $1,2,6,7,8$ and 9 , were based on the fact that they can help in balancing the workload across different departments and increase the efficiency and effectiveness of the production line. In the tailoring section, two sewing machines and their operators were removed. Also three tape-edge machines and three operators were removed from the system. In the packing section, one packing machine and one packing operator were removed. After applying the suggested alterations and running the improved scenario, the following results were obtained.

In all, 23,353 units of packed mattresses were produced and exited the system, as shown in Table 7. Comparing this number with the demand levels, shown in Table 1, confirms that the mattress production line will be able to meet the demand during all of the following five years of the expansion plan. The demand level in the year 2016 is 22,321 units of packed mattresses per month, which means that the improved production line has the capacity to produce over 1,000 extra units per month. 


\section{Khalili and Zahedi}

Table 7: Status summary of the entities involved in the production line (scenario).

\begin{tabular}{|l|r|r|r|r|}
\hline \multicolumn{5}{|c|}{ Entity summary } \\
\hline Name & \multicolumn{1}{|c|}{ Total Exits } & $\begin{array}{c}\text { Average Time in } \\
\text { System (Min) }\end{array}$ & $\begin{array}{c}\text { Average Time } \\
\text { Waiting (Min) }\end{array}$ & $\begin{array}{c}\text { Average Time in } \\
\text { Operation (Min) }\end{array}$ \\
\hline Coil & $6,600,672$ & 3.10 & 2.70 & 0.02 \\
\hline Chassis & 28,206 & 6.85 & - & 4.16 \\
\hline Frame & 72,988 & 0.68 & 0.23 & 0.45 \\
\hline Ready Panel & 46,870 & 11.15 & 5.72 & 2.92 \\
\hline Packed Mattress & 23,353 & $4,936.01$ & $4,849.50$ & 22.40 \\
\hline
\end{tabular}

\section{DISCUSSION AND CONCLUSIONS}

Based on the obtained results, the potential number of produced packed mattresses increased by $49.19 \%$ from 15,653 to 23,353 units per month. This quantity is enough to meet the monthly market demand until the year 2016. The main reason behind the increase in the production throughput is the improvement made in the padding section. The results of the improved scenario show that the padding section was an actual bottleneck in the system. The addition of three padding tables and five padding operators not only helped in increasing the throughput but also in having a more efficient and effective production line. As shown in Figure 6, the utilization of the padding section was improved by $4.4 \%$, from $92.82 \%$ to $96.95 \%$. Adding three padding processing tables could also be financially justifiable on the basis of the increase in the productivity of the production line and meeting the market demand.

Even though other improvements had no direct influence on the productivity of the production line, they helped in improving the utilization of other sections such as sewing, tape-Edge, and packing machines. Assuming those sections were overdesigned to start with, discarding two sewing and three tape-Edge and one packing machine, helped in increasing their utilizations to $71.61 \%, 83.42 \%$ and $22.9 \%$, respectively.

The utilization of some of the operators was also improved as a result of the suggested alterations 1, 2, 6, 7, 8 and 9, as shown in Figure 7. The frame bending operator's utilization fell by a half and reached $50 \%$ after adding another operator. Tape-Edge operators utilization was doubled to reach $93.32 \%$ after removing three operators. And the utilization of Sewing machine operators increased to $76.57 \%$ after removing two operators. The utilization of the packing operator was more than tripled, nearly $335 \%$, changing from $20.73 \%$ to $69.54 \%$. And the utilization of the padding operators decreased by $15.7 \%$ and reached $84.3 \%$. The results of the proposed changes suggest that the total number of operators remains the same; however, few operators need to be reallocated and trained to perform new tasks in different departments. This study mainly focused on the modeling of a mattress production line using the ProModel software in order to help in the production planning and decision making processes.

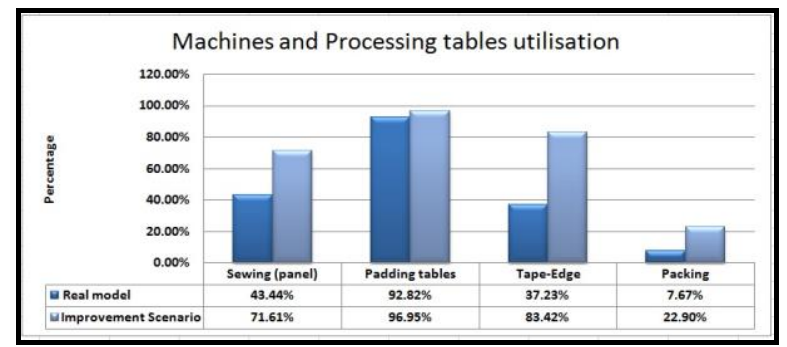

Figure 6: Machines and processing tables utilization.

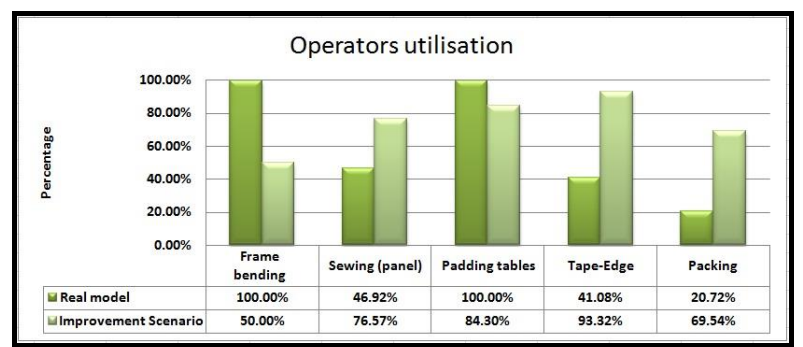

Figure 7: The comparison of resources' utilization.

By using the model, the management was able to investigate whether the mattress production line could cope with the expansion plan and meet the demand of the market over the next five years. This simulation study provides strong prospects for future research in the same manufacturing environment. 


\section{Khalili and Zahedi}

\section{REFERENCES}

Abu-Taieh, E., and A. A. Sheikh. 2009. "Commercial Simulation Packages: A Comparative Study." International Journal of Simulation Modeling 8(2):66-76.

Alexopoulos, C. 2006. "A Comprehensive Review of Methods for Simulation Output Analysis." In Proceedings of the 2006 Winter Simulation Conference, edited by L. F. Perrone, F. P. Wieland, J. Liu, B. G. Lawson, D. M. Nicol, and R. M. Fujimoto, 168-178. Piscataway, New Jersey: IEEE, Inc.

Rockwell Automation. 2012. Arena Simulation Software. Accessed April 17. http://www.arenasimulation.com

Carrie, A. 1988. Simulation of Manufacturing Systems. East Kilbride: John Wiley \& Sons Ltd.

Clark, G. M. 1996. "Introduction to Manufacturing Applications." In Proceedings of the 1996 Winter Simulation Conference, edited by J. M. Charnes, D. J. Morrice, D. T. Brunner, and J. J. Swain, 85-92. Piscataway, New Jersey: IEEE, Inc.

Clark, R., and D. Krahl. 2011. "Roadmap to Success: Your First Simulation Model." In Proceedings of the 2011 Winter Simulation Conference, edited by S. Jain, R. R. Creasey, J. Himmelspach, K. P. White, and M. Fu, 1470-1480. Piscataway, New Jersey: IEEE, Inc.

Dewa, M., and L. Chidzuu. 2012. "Bottleneck Management Through Discrete Event Simulation for Manual Automobile Assembly Systems." In proceedings of the 2012 CIE42, 121-132. Cape Town: CIE and SAIIE.

Grant, D. 2002. "A Wider View of Business Process Reengineering." Communications of the ACM 45(2):85-90.

Harrell, C., B. Ghosh, and R. Bowden. 2012. Simulation Using ProModel. 3rd ed. New York: McGrawHill, Inc.

Harrell, C. R., and R. N. Price. 2002. "Simulation Modeling Using ProModel Technology." In Proceedings of the 2002 Winter Simulation Conference, edited by E. Yücesan, C. H. Chen, J. L. Snowdon, and J. M. Charnes, 192-198. Piscataway, New Jersey: IEEE, Inc.

Hoad, K., and S. Robinson. 2011. "Implementing MSER-5 in Commercial Simulation Software and its Wider Implications." In Proceedings of the 2011 Winter Simulation Conference, edited by S. Jain, R.

R. Creasey, J. Himmelspach, K. P. White, and M. Fu, 495-503. Piscataway, New Jersey: IEEE, Inc.

Hoad, K., S. Robinson, and R. Davies. 2007. "Automating DES Output Analysis: How Many Replications to Run." In Proceedings of the 2007 Winter Simulation Conference, edited by S. G. Henderson, B. Biller, M. H. Hsieh, J. Shortle, J. D. Tew, and R. R. Barton, 505-512. Piscataway, New Jersey: IEEE, Inc.

Hoad, K., S. Robinson, and R. Davies. 2008. "Automating Warm-Up Length Estimation.” In Proceedings of the 2008 Winter Simulation Conference, edited by S. J. Mason, R. R. Hill, L. Mönch, O. Rose, T. Jefferson, J. W. Fowler, 532-540. Piscataway, New Jersey: IEEE, Inc.

Hoad, K., S. Robinson, and R. Davies. 2009. "Automating Discrete Event Simulation Output Analysis Automatic Estimation of Number of Replications, Warm-Up Period and Run Length." In Proceedings of the 2009 INFORMS Simulation Society Research Workshop, edited by L. H. Lee, M. E. Kuhl, J. W. Fowler, and S. Robinson, 75-79. Coventry: The University of Warwick.

Hoad, K., S. Robinson, and R. Davies,. 2011. "Autosimoa: A Framework for Automated Analysis of Simulation Output." Journal of Simulation 5(1):9-24.

Son, Y., A. T. Jones, and R. A. Wysk. 2003. "Component Based Simulation Modeling from Neutral Component Libraries." Computers and Industrial Engineering 45(1):141-165.

Lu, M. and L. Wong. 2005. "Comparing ProModel and SDESA in Modeling Construction Operations." In Proceedings of the 2005 Winter Simulation Conference, edited by M. E. Kuhl, N. M. Steiger, F. B. Armstrong, and J. A. Joines, 1524-1532. Piscataway, New Jersey: IEEE, Inc.

Nikoukara, J. and R. J. Paul. 1999. "Software Selection for Simulation in Manufacturing: A Review." Simulation Practice and Theory 7(1):1-14. 


\section{Khalili and Zahedi}

Nuyens, R., V. Dijk, V. Wassenhove, and E. Yücesan. 1996. "An Experimental Analysis of Steady-State Convergence in Simple Queueing Systems: Implications for Flexible Manufacturing System Models." Simulation Practice and Theory 4(1):1-29.

ProModel Corporation. 2011. ProModel User Guide. United States: ProModel Corporation.

Qayyum, A., and K. Dalgarno. 2012. "Improving Manufacturing Systems Through Use of Simulation." Technical Report, School of Mechanical and Systems Engineering, Newcastle University, Newcastle.

Quackenbush, J. 1968. "Inspection Department Manpower Planning Using Simulation Models." In Proceedings of the 1968 Winter Simulation Conference, 104-107. Piscataway, New Jersey: IEEE, Inc.

Robinson, S. 2007. "A Statistical Process Control Approach to Selecting a Warm-Up Period for a Discrete Event Simulation." European Journal of Operational Research 176(1):332-346.

Silva, L., A. L. Ramos, and P. M. Vilarinho. 2000. "Using Simulation for Manufacturing Process Reengineering- A Practical Case Study." In Proceedings of the 2000 Winter Simulation Conference, edited by J. A. Joines, R. R. Barton, K. Kang, and P. A. Fishwick, 104-107. Piscataway, New Jersey: IEEE, Inc.

Tearwattanarattikal, P., S. Namphacharoen, and C. Chamrasporn. 2008. "Using ProModel as a Simulation Tool to Assist Plant Layout Design and Planning: Case Study Plastic Packaging Factory." Songklanakarin Journal of Science and Technology 30(1):117-123.

Tewoldeberhan, T. W., A. Verbraeck, E. Valentin, and G. Bardonnet. 2002. "An Evaluation and Selection Methodology for Discrete-Event Simulation Software." In Proceedings of the 2002 Winter Simulation Conference, edited by E. Yücesan, C. H. Chen, J. L. Snowdon, and J. M. Charnes, 67-75. Piscataway, New Jersey: IEEE, Inc.

Weiss, Z., and M. Pilacinska. 2005. "Data Collection for Systems of Production Simulation." In Proceedings of the 2005 European Conference on Modeling and Simulation, edited by Y. Merkuryev, R. Zobel, and E. Kerckhoffs, 364-369. Riga: ECMS.

Williams, E. J., and R. Narayanaswamy. 1997. "Application of Simulation to Scheduling, Sequencing, and Material Handling." In Proceedings of the 1997 Winter Simulation Conference, edited by S. Andradóttir, K. J. Healy, D. H. Withers, and B. L. Nelson, 861-865. Piscataway, New Jersey: IEEE, Inc.

\section{AUTHOR BIOGRAPHIES}

MOHAMMAD H. KHALILI obtained his Master of Science degree from University of Salford in 2013. He received his Bachelor of Science degree in Industrial Engineering from University of Sharjah in the United Arab Emirates. He has worked in various collaborative studies with different local companies as part of his degree requirements. He worked in a simulation project for an air duct manufacturing company where the Arena Simulation Software was used for the purpose of modeling the manufacturing system. His latest simulation project was based on a six months internship at a mattress manufacturing company where he worked as an improvement engineer. Mohammad H. Khalili's contact email address is khalilimohd@gmail.com.

FARHAD ZAHEDI is a Senior Lecturer, specializing in Computer Aided Design and Simulation modeling of Manufacturing Systems. He obtained his Master of Science degree from Strathclyde University in 1985 before working at Napier University of Edinburgh. He has worked with a number of simulation packages in the past, including SEE-WHY and Siman/Cinema, and currently with ProModel, teaching at University of Salford in Manchester, Great Britain. He has worked as a simulation analyst for companies such as Unisys and has collaborated in various research projects. His main interests are in Process Simulation and Maintenance Operations Modeling. Farhad is the Director of Industrial Placement (UK) at the School of Computing, Science and Engineering and is the Programme Leader for the MSc in Manufacturing Systems and Management. Farhad Zahedi can be contacted at f.zahedi@salford.ac.uk. 